\title{
Significance analysis study on stability of long-span curve continuous rigid frame bridge with high pier
}

\author{
Changqing Wang \\ CCCC Second Highway Consultants Co.Ltd, Wuhan, China
}

\begin{abstract}
KEYWORD: High pier; Long-span; Continuous rigid frame bridge; Stability parameters; Significance analysis

ABSTRACT: In order to improve the safety of long-span curve continuous rigid frame bridge with high piers, the $\mathrm{Wu}$ Jiawan bridge is taken as an example, the finite element model of the full-scale bridge is established by using Midas/civil, the construction process is simulated by calculation. The stability of the highest pier, the stability of the longest cantilever and the stability in complete stage of the bridge under different working conditions was analyzed. The buckling load factor of bridge in service stage under different radius of curvature, different way of loading and different temperature was calculated. Types of buckling in different conditions was analyzed contrastively, the significance analysis of stability parameters was researched. The results show that wind load in different directions has little effect on stability of pier in the stage of highest pier, longitudinal wind load has more negative influence on stability than transverse wind load in the stage of longest cantilever. In the complete stage of bridge, the situation that all vehicles traveling in the lane outside of curve is more dangerous than the situation that all vehicles traveling in the lane inside of curve.
\end{abstract}

\section{INTRODUCTION}

With the advantage of spanning ability, construction technology and driving comfort, continuous rigid frame bridge with high pier is the most popular form in complex mountain terrain. In order to reduce weight, double thin-walled pier is widely applied. Curved bridge has advantage in adjust adverse ter-rain. Meanwhile, the stability of long-span continuous rigid frame bridge with high pier caused a series of accidents. For example, Мозыр bridge collapsed due to the instability of the pressure bar and West Gate bridge collapsed due to flange buckled.

Liu et al.(2013) analyzed Shandian River continuous rigid frame bridge with high pier, the stability in construction stage and complete stage of the bridge was calculated. By analyzing buckling load factor of bridge in construction and complete stage, Liu et al. (2005) found stability of bridge under stage of maximum double cantilever was low. Zhou et al.(2014) analyzed stability of bridge in stage of construction under different loads. Yang and Chen(2010) studied the bridge stability in the longest cantilever status under nine working conditions, considering effects of wind load and the situation that hanging basket suddenly drop on the stability.

However, research on stability of long-span continuous rigid frame bridge with high piers, focusing on curved bridge was not much. And many of them didn't consider the effect of curvature radius on stability. It was fail to give a clear conclusion that the influence degree of various factors on stability.

The Wu Jiawan Bridge is taken as an example in this paper. After a finite element model is established based on Midas/civil, the stability of highest pier, the longest cantilever and the stability in complete stage of curved bridge was analyzed. And a series factor levels of about curvature radius was set to contrast the buck-ling load factor of bridge. Then, the design parameter significance analysis on the structural stability were carried out based on MATLAB.

\section{BRIDGE DESCRIPTION AND FINITE ELEMENT MODEL}

\section{Bridge Description}

The Wu Jiawan Bridge, as shown in Figure 1, is lo-cated in Zunyi, Guizhou Province. The bridge was constructed in the form of long span, continuous rig-id frame, high piers and curved bridge. The 
span $(58+100+58) \mathrm{m}$. The superstructure of bridge was de-signed for hanging basket cantilever castin-place construction, the substructure $1 \#$ and $2 \#$ was main piers with double-limb rectangle thinwall, the height of piers were $60 \mathrm{~m}$ and $42 \mathrm{~m}$.

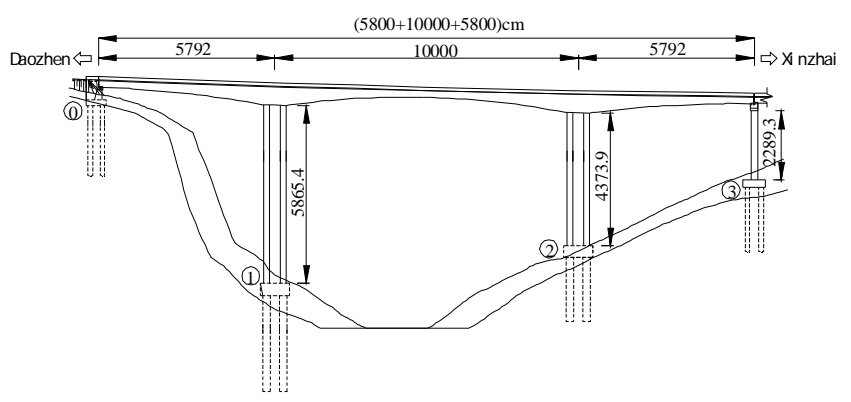

\section{Finite Element Model}

Figure 1. The Wu Jiawan Bridge.

The finite element model of the full-scale bridge is established by using Midas/civil 2013 with 152 elements and 159 nodes. The boundary condition of model: the bottom of the pile caps and the foundation is consolidation, double limb end of the pier and pile caps is master-slave node of rigid connection, thin-walled pier and girder adopt stiffness in elastic connection. The finite element model of Wu Jiawan Bridge is shown in Figure 2.

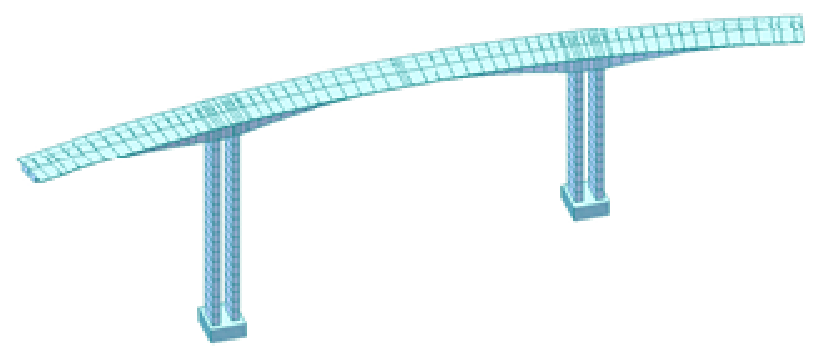

Figure 2. The finite element model of Wu Jiawan Bridge.

\section{MODEL ANALYSIS OF BRIDGE}

\section{Stability of Highest Pier}

With the increase of the height of pier, the stability of pier will change under the self-weight, wind load, other internal and external factors. The stability of high pier at this stage is relate to the safety and progress of the construction. At this stage, the highest state of 1\# pier was selected to make stability analysis. The bare pier structure can be regarded as vertical cantilever beam on the foundation set. The highest pier model for stability analysis is shown in Figure 3.

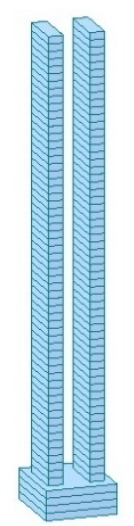

Figure 3. The highest pier model for stability analysis. 
As a statically determinate structure, the effect of uniform temperature and gradient temperature was neglected. The effects of this stage are as follows:

(1)self-weight of pier

(2)transverse wind load of pier(at the bottom of pier $q_{1}=2.86 \mathrm{kN} / \mathrm{m}$, at the top of pier $\left.q_{2}=5.06 \mathrm{kN} / \mathrm{m}\right)$

(3)longitudinal wind load of pier(at the bottom of pier $q_{1}=2.86 \mathrm{kN} / \mathrm{m}$, at the top of $\left.\operatorname{pier} q_{2}=5.06 \mathrm{kN} / \mathrm{m}\right)$.

design situation 1: (1)+(2); design situation 2: (1)+(3);

design situation 3: (1);

The buckling load factor under different situations are shown in Table 1.

Table 1. Buckling load factor

\begin{tabular}{lllll}
\hline Design & \multicolumn{4}{l}{ Buckling load factor $\lambda$} \\
\cline { 2 - 5 } Situation & $1^{\text {st }}$ & $2^{\text {nd }}$ & $3^{\text {rd }}$ & $4^{\text {th }}$ \\
& mode & mode & mode & mode \\
\hline 1 & 15.06 & 15.10 & 106.71 & 106.97 \\
2 & 15.06 & 15.10 & 106.78 & 107.04 \\
3 & 15.06 & 15.10 & 106.78 & 107.04 \\
\hline
\end{tabular}

\section{Stability of Cast-in-Place Cantilever Construction}

For long-span curve continuous rigid frame bridge with high piers, in the process of cast-in-place cantilever construction, the partial load produced by the process of unbalanced construction, wind load and the situation that hanging basket suddenly drop have a negative influence on the stability of structure. The model for stability analysis in this stage is shown in Figure 4.

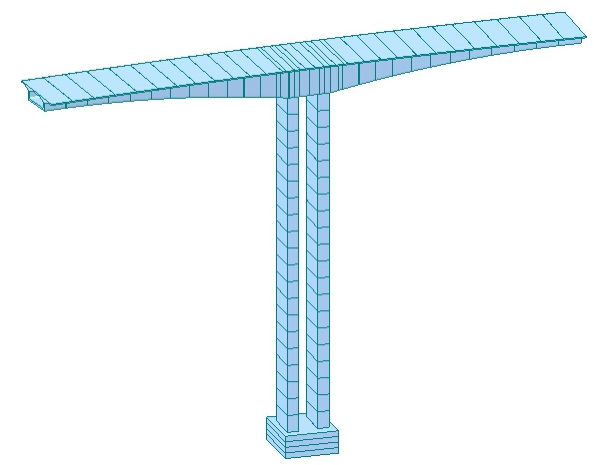

Figure 4. The model for stability analysis in this stage.

Thus, the state of the longest cantilever was selected as the most disadvantage state. Therefore, the effects of this stage are as follows:

(1)self-weight

(2)different in weight between two sides of cantilever( 0.95 times in weight of the beam was taken on the left, 1.05 times in weight of the beam was taken on the right)

(3)load produced by asymmetric cast-in-place cantilever construction(dynamic coefficient on the left was 0.8 , dynamic coefficient on the right was 1.2)

(4)wet weight

(5)transverse wind load of pier(at the bottom of pier $q_{1}=2.86 \mathrm{kN} / \mathrm{m}$, at the top of pier $\left.q_{2}=5.06 \mathrm{kN} / \mathrm{m}\right)$

(6)longitudinal wind load of pier(at the bottom of pier $q_{1}=6.50 \mathrm{kN} / \mathrm{m}$, at the top of pier $q_{2}=11.51 \mathrm{kN} / \mathrm{m}$ ) 
(7)load of hanging basket $(650 \mathrm{KN})$

(8)hanging basket suddenly drop(dynamic coefficient was 2.0)

(9)rise in gradient temperature $\left(\mathrm{T}_{1}=14^{\circ} \mathrm{C}, \mathrm{T}_{2}=5.5^{\circ} \mathrm{C}\right)$

(10)drop in gradient temperature $\left(\mathrm{T}_{1}=-7^{\circ} \mathrm{C}, \mathrm{T}_{2}=-2.75^{\circ} \mathrm{C}\right)$

design situation $1:(1)+(2)+(3)+(4)+(5)+(7)+(9)$

design situation $2:(1)+(2)+(3)+(4)+(5)+(7)+(10)$

design situation $3:(1)+(2)+(3)+(4)+(5)+(8)+(9)$

design situation $4:(1)+(2)+(3)+(4)+(5)+(8)+(10)$

design situation $5:(1)+(2)+(3)+(4)+(6)+(7)+(9)$

design situation $6:(1)+(2)+(3)+(4)+(6)+(7)+(10)$

design situation $7:(1)+(2)+(3)+(4)+(6)+(8)+(9)$

design situation 8: $(1)+(2)+(3)+(4)+(6)+(8)+(10)$

The buckling load factor under different situations are shown in Table 2.

Table 2. Buckling load factor

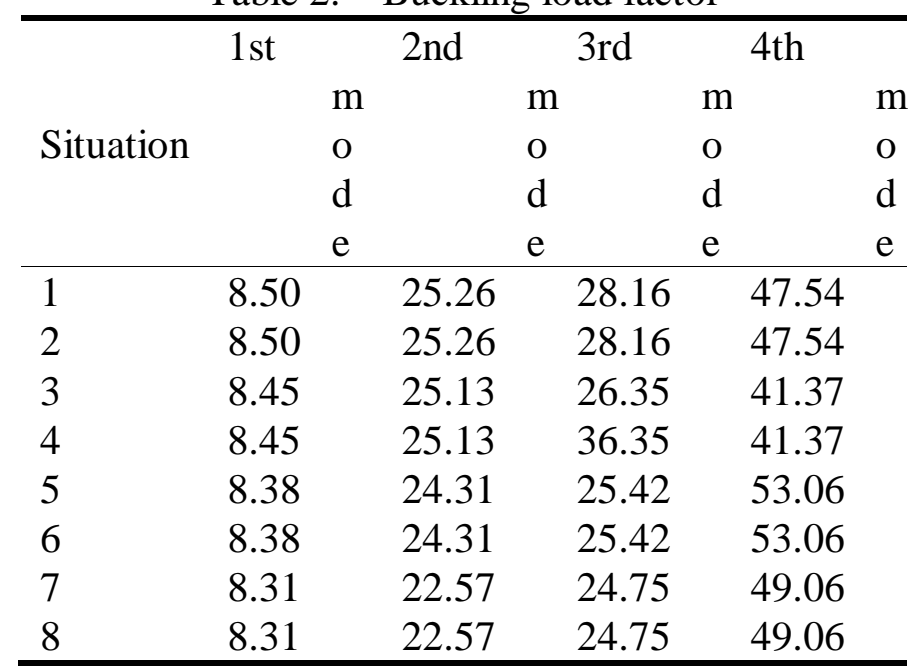

The orthogonal test with three factors and two levels was carried out based on matlab. Then, signif-icance analysis of buckling load factor under different situations was made. The first factor is wind load, it has two levels, namely (5) and (6); the second factor is load of hanging basket, it has two levels, namely (7) and (8); the third factor is temperature effect, it has two levels, namely (9) and (10).

In the case of the confidence level of $95 \%$, the significant variance analysis results are shown in Table 3.

Table 3. Significant variance analysis

\begin{tabular}{cclcc}
\hline $\begin{array}{c}\text { Fac- } \\
\text { tor }\end{array}$ & $1^{\text {st }}$ mode & $2^{\text {nd }}$ mode & $3^{\text {rd }}$ mode & $4^{\text {th }}$ mode \\
\hline First & signifi- & signifi- & signifi- & signifi- \\
& cant & cant & cant & cant \\
Secon & signifi- & signifi- & insignifi- & signifi- \\
d & cant & cant & cant & cant \\
Third & $\begin{array}{c}\text { insignifi- } \\
\text { insignifi- }\end{array}$ & insignifi- & insignifi- \\
& cant & cant & cant & cant \\
\hline
\end{tabular}

\section{Stability in Complete Stage of Bridge}

After closure of long-span curved continuous rigid frame bridge with high piers, the bridge system transformed statically determinate structure into statically indeterminate structure. The stability in complete stage of the bridge have an important influence on safety of bridge. For curved bridge in 
this case, influence of different curvature radius, traveling eccentricity of vehicles, temperature effect on stability of bridge were considered.

The curvature radius of this case is $750 \mathrm{~m}$. In the condition of the same span, curved bridge with curvature radius at $450 \mathrm{~m}, 550 \mathrm{~m}, 650 \mathrm{~m}, 750 \mathrm{~m}, 850 \mathrm{~m}, 950 \mathrm{~m}, 1050 \mathrm{~m}$ was set. As the characteristics of multi-lane in this case, traveling eccentricity of vehicles should be considered. Then, the four ways of traveling eccentricity of vehicles are as follows:

(1) all vehicles traveling in the lane outside of curve

(2)all vehicles traveling in the middle lane

(3)all vehicles traveling in the lane inside of curve

(4) all vehicles traveling in all lanes

Therefore, the effects of this stage are as follows:

(1)self-weight

(2)secondary dead load $q=65.4 \mathrm{KN} / \mathrm{m}$

(3)vehicles load(impact effects) $\mu=0.068$,

$q_{k}=11.214 \mathrm{kN} / \mathrm{m}, P_{k}=384.48 \mathrm{kN}$

(4)vehicles brake force (at the top of $1 \# P_{1}=5.22 \mathrm{kN}$, at the top of $2 \# P_{2}=7.46 \mathrm{kN}$ )

(5)transverse wind load of pier(at the bottom of pier $q_{1}=2.86 \mathrm{kN} / \mathrm{m}$, at the top of pier $q_{2}=5.06 \mathrm{kN} / \mathrm{m}$, superstructure $q_{3}=7.3 \mathrm{kN} / \mathrm{m}$ )

(6)longitudinal wind load of pier(at the bottom of pier $q_{1}=6.50 \mathrm{kN} / \mathrm{m}$, at the top of pier $\left.q_{2}=11.51 \mathrm{kN} / \mathrm{m}\right)$

(7)rise in gradient temperature $\left(\mathrm{T}_{1}=14^{\circ} \mathrm{C}, \mathrm{T}_{2}=5.5^{\circ} \mathrm{C}\right)$

(8)drop in gradient temperature $\left(\mathrm{T}_{1}=-7^{\circ} \mathrm{C}, \mathrm{T}_{2}=-2.75^{\circ} \mathrm{C}\right)$

(9)rise in uniform temperature $\left(\mathrm{T}_{0}=15^{\circ} \mathrm{C}, \Delta \mathrm{T}=25^{\circ} \mathrm{C}\right)$

(10)drop in uniform temperature $\left(\mathrm{T}_{0}=15^{\circ} \mathrm{C}, \Delta \mathrm{T}=-25^{\circ} \mathrm{C}\right)$

design situation $1:(1)+(2)+(3)+(4)+(5)+(6)+(7)+(9)$

design situation $2:(1)+(2)+(3)+(4)+(5)+(6)+(7)+(10)$

design situation $3:(1)+(2)+(3)+(4)+(5)+(6)+(8)+(9)$

design situation $4:(1)+(2)+(3)+(4)+(5)+(6)+(8)+(10)$

The buckling load factor with different curvature radius under different situations are shown in Figure 5 to Figure 8.

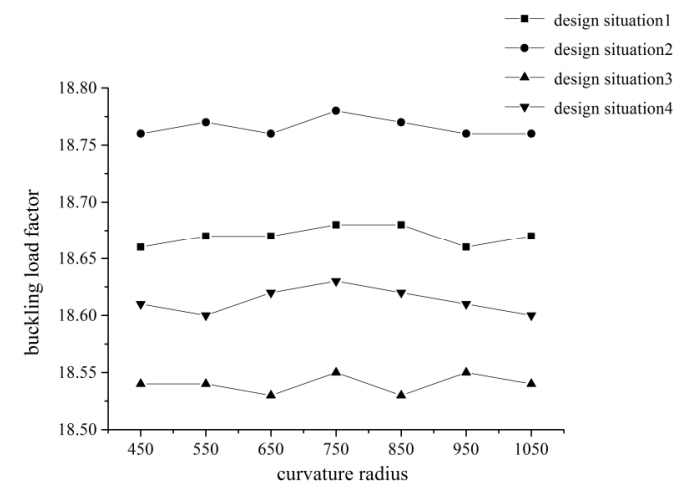

Figure 5(a). The buckling load factor of 1st mode. 


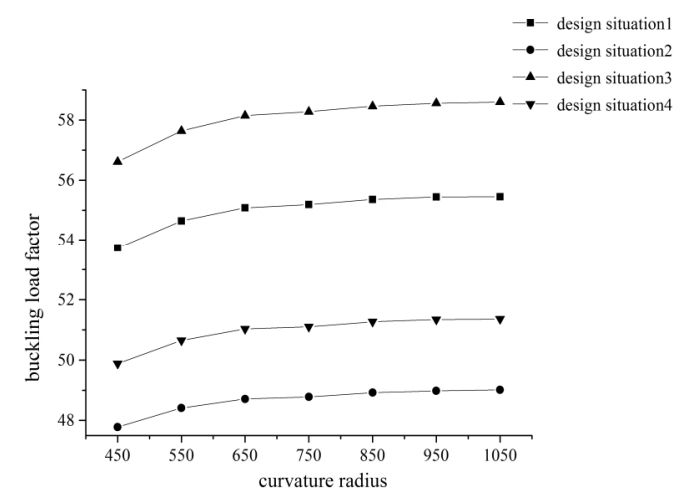

Figure 5(b). The buckling load factor of 3rd mode.

Figure 5. All vehicles traveling in the lane outside of curve.

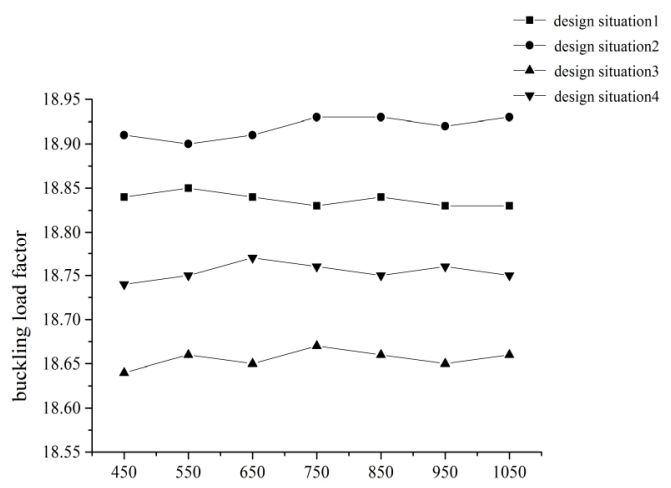

Figure 6(a). The buckling load factor of 1 st mode.

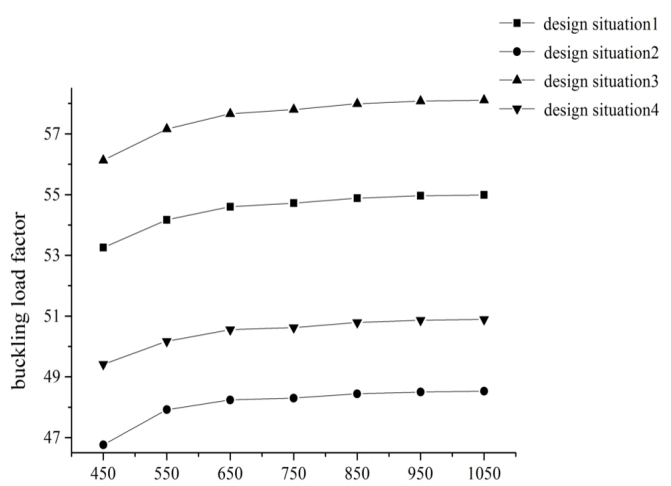

Figure 6(b). The buckling load factor of 3rd mode.

Figure 6. All vehicles traveling in the middle lane 


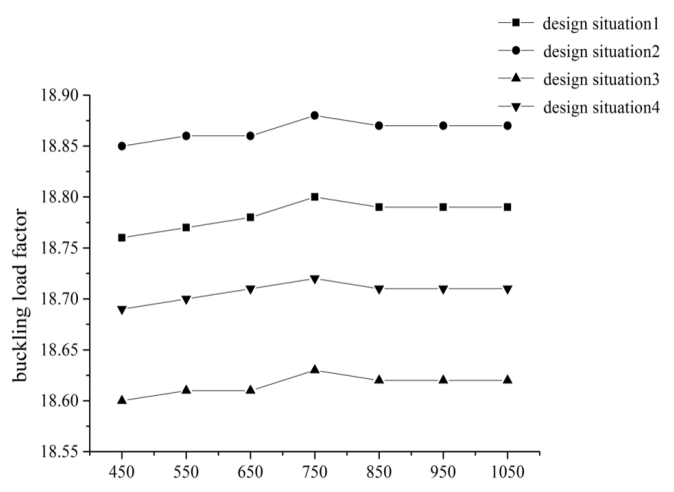

Figure 7(a). The buckling load factor of 1st mode.

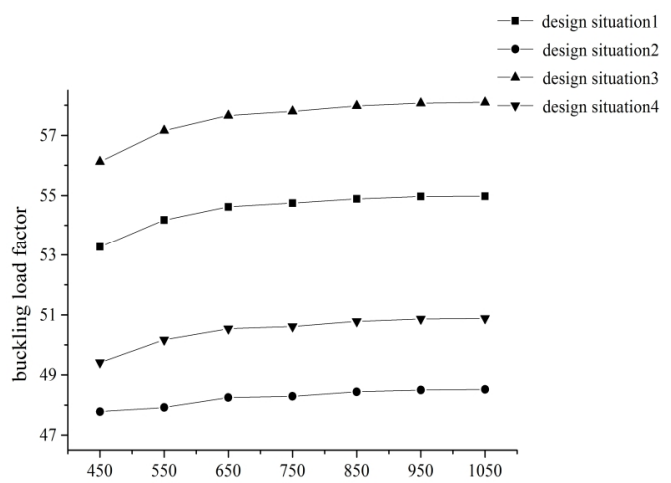

Figure 7(b). The buckling load factor of 3rd mode.

Figure 7. All vehicles traveling in the lane inside of curve.

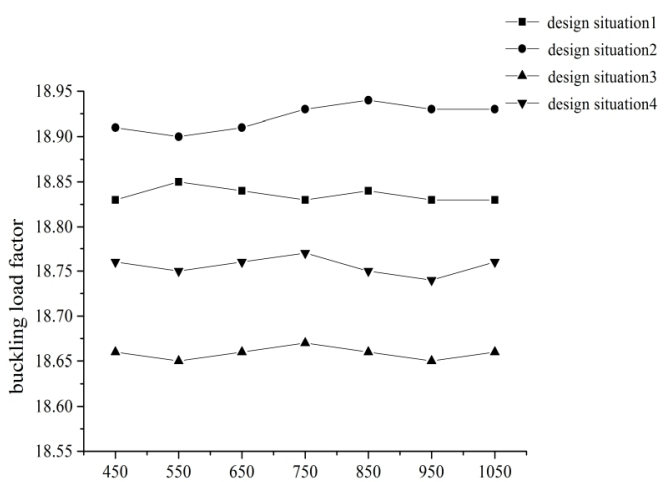

Figure $8(\mathrm{a})$. The buckling load factor of $1^{\text {st }}$ mode.

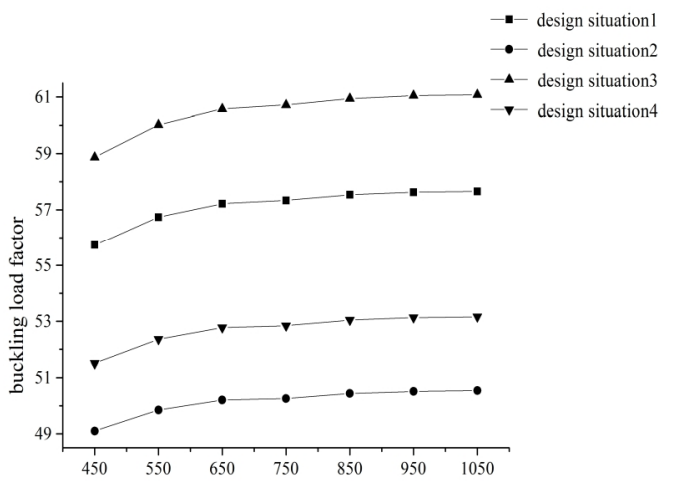

Figure 8(b). The buckling load factor of $3^{\text {rd }}$ mode

Figure 8. All vehicles traveling in all lanes. 
The orthogonal test with four factors and mixed-level was carried out based on matlab, the interaction between different factors was considered. Then, sig-nificance analysis of buckling load factor under dif-ferent situations was made. The first factor(A) is curvature radius, it has seven levels, namely $450 \mathrm{~m}, 550 \mathrm{~m}, 650 \mathrm{~m}, 750 \mathrm{~m}, 850 \mathrm{~m}, 950 \mathrm{~m}, 1050 \mathrm{~m}$; the sec-ond factor(B) is the ways of traveling eccentricity of vehicles, it has four levels, namely (1)、 (2)、 (3)、 (4); the third factor(C) is gradient temperature, it has two levels, namely (7) and (8); the fourth factor(D) is uniform temperature, it has two levels, namely (9) and (10).

In the case of the confidence level of $95 \%$, the significant variance analysis results are shown in are shown in Figure 9 to Figure 10.

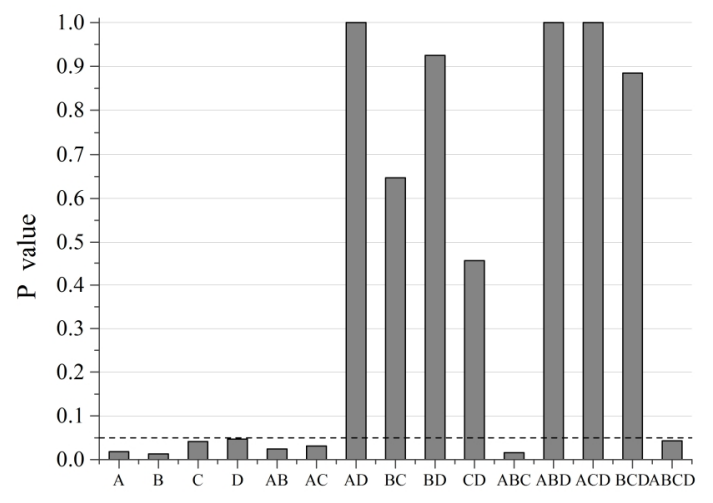

Figure 9. Significant of $\mathrm{P}$ value for 1st mode buckling load factor.

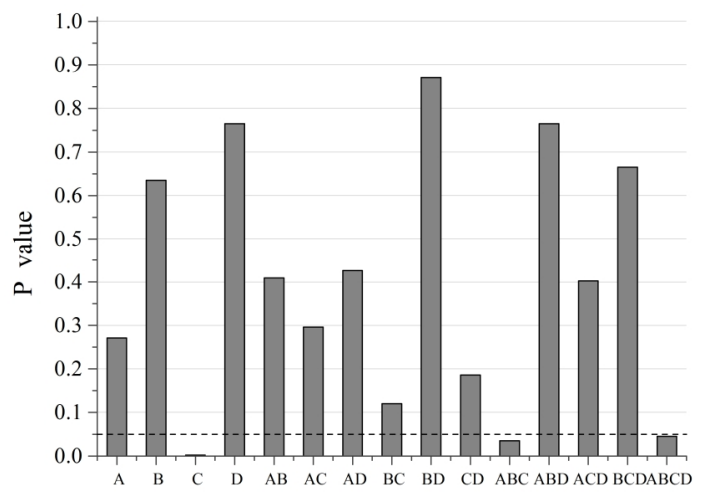

Figure 10. Significant of $\mathrm{P}$ value for $3^{\text {rd }}$ mode buckling load factor.

\section{SUMMARY AND CONCLUSIONS}

The Wu Jiawan Bridge was taken as an example in this paper, stability of bridge with the whole process was analyzed. The influence of different curvature radius, traveling eccentricity of vehicles, temperature effect on stability of bridge were considered, and the design parameter significance analysis on the structural stability were carried out.

(1) In the stage of highest pier, wind load in different directions has little effect on stability of pier. In the stage of longest cantilever, wind load has a significant influence on stability of bridge.

(2) In the complete stage of bridge, the situation that all vehicles traveling in the middle lanes is the most safety way. The situation that all vehicles traveling in the lane outside of curve is more dangerous than the situation that all vehicles traveling in the lane inside of curve.

(3) In the complete stage of bridge, gradient tem-perature has a significant influence on stability of bridge under high-order mode of buckling. The curvature radius, traveling eccentricity of vehicles, 
gradient temperature, uniform temperature have a significant influence on stability of bridge under low-order mode of buckling.

\section{REFERENCES}

Chen, T. 2009. Stability analysis of continuous rigid frame bridge with high pier and large span. Master's thesis, Xi'an University of Architecture and Technology.

$\mathrm{Hu}, \mathrm{H}$. 2007. Static wind stability analysis of long-span continuous bridge during cantilever construction. Journal of China and Foreign Highway 27(6):97-99.

Li, G.H. 2009. Stability and vibration of bridge structure. Beijing: China Railway Publishing House.

Liu, R. et al. 2013. Design and key technologies of shandian river bridge on high pier continuous rigid frame bridge. Highway Engineering 38(2):125-129.

Liu, Z.H. et al. 2005. Stability anal-ysis of long-span continuous rigid frame bridge with high pier. Journal of China and Foreign Highway 25(6):63-66.

Ma, X.H. \& Yu, Y. 2012. Analysis of parameter sensitivi-ty of construction control of high-rise pier and long span con-tinuous rigid-frame bridge. Bridge Construction 42(3):57-62.

Wang, F. et al. 2012. Analysis of stabil-ity of long-span continuous rigid frame bridge with high pier. Journal of Railway Engineering Society 10:57-62.

Wang, J.L. \& He, S.H. 2007. Central angle influence of long-span curve bridge on its inner forces, displacements and stability. Journal of Traffic and Transportation Engineering 7(3):86-90.

Yang, S.K. \& Chen, S.X. 2010. Analysis and study on stability of high-pier and large-span continuous rigid frame bridge during construction. Journal of Railway Engineering Society 12:51-55.

Zhou, L.P. et al. 2014. Stability analysis of high pier and long-span continuous rigid frame bridge construc-tion. Highway Engineering 39(4):226-230. 